\title{
OS ÓRFÃOS DO CONSTRUTIVISMO
}

\section{LOS HUÉRFANOS DEL CONSTRUCTIVISMO}

THE ORPHANS OF CONSTRUCTIVISM

\author{
Maria do Rosário Longo MORTATTI ${ }^{1}$
}

RESUMO: No Brasil, a relação entre a necessidade de superação dos problemas sociais, políticos e educacionais, gerados pela ditadura militar instaurada em 1964, e a busca de respostas didático-pedagógicas para os problemas da alfabetização e do analfabetismo encontrou sua síntese na teoria construtivista resultante das pesquisas de Emilia Ferreiro e por ela apresentada como "revolução conceitual" em alfabetização. Inicialmente, essa teoria se caracterizava como contra-hegemônica, no conjunto de ideias e práticas pedagógicas "de esquerda", e seus disseminadores a apresentavam como promessa de superação dos problemas da a alfabetização das "classes populares" e dos "filhos do analfabetismo". Nas últimas três décadas, porém, essa teoria se consolidou como hegemônica (e não apenas para a alfabetização e para a escola pública), tendo configurado um "construtivismo à brasileira", fundador de uma nova tradição que identifica o "quarto momento crucial" (ainda em curso) da história da alfabetização no Brasil. E hoje se pode avaliar que a introdução e a consolidação do construtivismo como fundamento teórico de políticas educacionais contribuíram, como desserviço, para criar gerações de "órfãos do construtivismo".

PALAVRAS-CHAVE: Alfabetização. Construtivismo. História da alfabetização. Brasil.

RESUMEN: En Brasil, la relación entre la necesidad de superación de los problemas sociales, políticos y educacionales, generados por la dictadura militar establecida en 1964, y la búsqueda de respuestas didáctico-pedagógicas para los problemas de la alfabetización y del analfabetismo encontró su síntesis en la teoría constructivista resultante de las investigaciones de Emilia Ferreiro y por ella presentada como "revolución conceptual' en alfabetización. Inicialmente, esa teoría se caracterizaba como contra-hegemónica, en el conjunto de ideas y prácticas pedagógicas "de izquierda", y sus diseminadores la presentaban como promesa de superación de los problemas políticos y didáctico-pedagógicos para la alfabetización de las "clases populares" y de los "hijos del analfabetismo". En las últimas tres décadas, sin embargo, esa teoría se consolidó como hegemónica (y no solamente para la alfabetización y para la escuela pública), ya que ha fundado, por medio de apropiaciones brasileñas, una nueva tradición que identifica el "cuarto momento crucial" (todavía en curso) de la historia de la alfabetización en Brasil. Y, hoy, se puede evaluar que la introducción y la consolidación del constructivismo como fundamento teórico de políticas educacionales contribuyeron, como perjuicio, para crear generaciones de "huérfanos del constructivismo".

${ }^{1}$ Professora Titular. Departamento de Educação - Faculdade de Filosofia e Ciências, FFC/UNESP. Coordenadora do Grupo de Pesquisa "História do Ensino de Língua e Literatura no Brasil", Marília, Brasil. E-mail: mrosario@marilia.unesp.br. 
PALABRAS CLAVE: Alfabetización. Constructivismo. Historia de la alfabetización. Brasil.

ABSTRACT: In Brazil, the relationship between the need to overcome social, political and educational problems generated by the military dictatorship established in 1964 and the search for didactic-pedagogical responses to the problems of literacy and illiteracy found its synthesis in the constructivist theory resulting from research by Emilia Ferreiro and presented by her as a "conceptual revolution" in literacy. Initially, this theory was characterized as counter hegemonic in the set of ideas and practices of "leftist", and its disseminators presented it as a promise of overcoming political and didactic-pedagogical problems for the literacy of the "popular classes" and "sons of illiteracy". In the last three decades, however, this theory has consolidated itself as hegemonic (and not only for literacy and public school), having founded, through Brazilian appropriations, a new tradition that identifies the "fourth crucial moment" (still current) in the history of literacy in Brazil. And nowadays one can evaluate that the introduction and consolidation of constructivism as a theoretical foundation of educational policies contributed, as a disservice, to create generations of "orphans of constructivism”.

KEYWORDS: Literacy. Constructivism. History of literacy. Brazil.

Para a concepção crítica, o analfabetismo nem é uma "chaga", nem uma "erva daninha" a ser erradicada, nem tampouco uma enfermidade, mas uma das expressões concretas de uma realidade social injusta. Não é um problema estritamente linguístico nem exclusivamente pedagógico, metodológico, mas político, como a alfabetização por meio da qual se pretende superá-lo. Proclamar a sua neutralidade, ingênua ou astutamente, não afeta em nada a sua politicidade intrínseca. (FREIRE, 2001).

\section{Introdução}

No Brasil, a relação entre a necessidade de superação dos problemas sociais, políticos e educacionais, gerados pela ditadura militar instaurada em 1964, e a busca de respostas didático-pedagógicas para os problemas da alfabetização e do analfabetismo encontrou sua síntese na teoria construtivista resultante das pesquisas de Emilia Ferreiro e por ela apresentada como "revolução conceitual" em alfabetização.

Inicialmente, essa teoria se caracterizava como contra-hegemônica, no conjunto de ideias e práticas pedagógicas "de esquerda", e seus disseminadores a apresentavam como promessa de superação dos problemas políticos e didático-pedagógicos para a alfabetização das "classes populares" e dos "filhos do analfabetismo" (FERREIRO, 1990). Nas últimas três décadas, porém, essa teoria se consolidou como hegemônica (e 
não apenas para a alfabetização e para a escola pública), tendo configurado um "construtivismo à brasileira", fundador de uma nova tradição que identifica o "quarto momento crucial" (ainda em curso) da história da alfabetização no Brasil ${ }^{2}$ (MORTATTI, 2000).

E hoje se pode avaliar que a introdução e a consolidação do "cavalo de Troia" (DUARTE, 2008) do construtivismo como fundamento teórico de políticas educacionais no Brasil, contribuíram, como desserviço, para acentuar ou renovar problemas da alfabetização escolar, de analfabetismo funcional e de formação de professores para a Educação Infantil e Anos Iniciais do Ensino Fundamental.

\section{A construção da hegemonia do construtivismo em alfabetização escolar no Brasil}

O processo de redemocratização do país propiciou a emersão, na década de 1980, de propostas pedagógicas contra-hegemônicas ${ }^{3}$ para a escola pública, as quais se caracterizavam como "pedagogias de esquerda", caracterizadas por certa ambiguidade e heterogeneidade entre seus propositores (SAVIANI, 2008, p.18).

No âmbito da alfabetização escolar, entendida como a base dos problemas do "fracasso escolar" gerado pelo governo ditatorial, essas características também estavam presentes em ideias e propostas democratizantes, em torno das quais se reuniam

${ }^{2}$ Em Mortatti (2000), proponho a divisão da história da alfabetização no Brasil, a partir do final do século XIX, em quatro momentos cruciais, cada um deles caracterizado por disputas entre defensores do "novo" e do "tradicional", tendo como referência constante a questão dos métodos de alfabetização (mesmo quando se trata de radical oposição a qualquer tipo de método). Motivadas pela necessidade de resolver os problemas da alfabetização, dessas disputas políticas resultou, em cada momento, a hegemonia de uma nova proposta (e um "novo" método ou um "não método" de alfabetização), configurando-se um novo sentido para a alfabetização e fundando-se também uma "nova tradição". Esses momentos e suas principais características são os seguintes: primeiro momento crucial (1876 a 1890) - disputa entre defensores do então "novo" método da palavração e os dos "antigos" métodos sintéticos (alfabético, fônico, silábico); segundo momento crucial (1890 a meados da década de 1920) - disputa entre defensores do então "novo" método analítico e os dos "antigos" métodos sintéticos; terceiro momento crucial (meados dos anos de 1920 a final da década de 1970) - disputas entre defensores dos "antigos" métodos de alfabetização (sintéticos e analíticos) e os dos então "novos" "testes ABC para verificação da maturidade necessária ao aprendizado da leitura e escrita", criados por M. B. Lourenço Filho, de que decorreu a introdução dos "novos" métodos mistos; quarto momento crucial (meados da década de 1980 aos dias atuais) - disputas entre os defensores da então "nova" teoria construtivista e os dos "antigos" testes de maturidade e dos "antigos" métodos de alfabetização.

3 "Do ponto de vista da relação da educação com a sociedade as teorias pedagógicas dividem-se em dois grandes grupos: aquelas que procuram orientar a educação no sentido da conservação da sociedade em que se insere, mantendo a ordem existente; e aquelas que buscam orientar a educação tendo em vista a transformação da sociedade, posicionando-se contra a ordem existente. As primeiras são chamadas "pedagogias hegemônicas" porque, correspondendo aos interesses dominantes, tendem a hegemonizar o campo educativo. As segundas transformar a ordem vigente". (SAVIANI, 2008, p.11). 
educadores representantes de grupos políticos diversos que combatiam a ditadura. A opção pelo construtivismo representou a principal semelhança entre representantes desses grupos políticos "de esquerda" (majoritariamente formados por educadores liberais progressistas e preocupados com fundamentação marxista) para elaboração de propostas oficiais para a alfabetização escolar (pública).

Nesse contexto, foi emblemática a atuação de primeira hora dos defensores oficiais e sistemáticos dessa nova teoria, na Secretaria de Educação do Estado de São Paulo (SEE/SP $)^{4}$. Durante a gestão do Governador Franco Montoro, a SEE/SP implementou o projeto do Ciclo Básico de Alfabetização (CB), como desencadeador de uma série de mudanças estruturais, administrativas e didático-pedagógicas, na rede pública de ensino paulista. E, para preencher o vazio pedagógico da proposta do $\mathrm{CB}$, foi introduzida a teoria construtivista, como avaliavam as educadoras Alves (apud FERREIRO, 1990) e Silva e Davis (1993):

[...] havia um clima favorável na rede educacional para essa discussão pedagógica, porque se sentia a necessidade de uma mudança, e porque se estimava que uma medida exclusivamente política não seria suficiente para modificar a prática. Estávamos procurando alguma coisa e, nesse momento, a produção teórica da Emilia veio preencher o vazio na proposta política do Ciclo Básico. (ALVES apud FERREIRO, 1990, p.6).

Essa clareza teórica orientou, no início dos anos 80, a gestação do CBA, em São Paulo. No entanto, além de ser uma proposta pedagógica, esta era também de natureza política, visto propor grande participação dos diferentes setores envolvidos no processo educativo na elaboração das diretrizes a serem tomadas. [...]

O Ciclo Básico de Alfabetização (CB) foi a principal medida de um conjunto de projetos pedagógicos voltados para a melhoria da qualidade do ensino, ampliação das oportunidades de acesso e permanência na escola pública e busca de maior aproveitamento da comunidade escolar (pais, professores e alunos) no sistema educacional. Concebido e implantado num cenário sombrio, vinha, todavia, iluminado por grandes esperanças de transformação da realidade escolar brasileira. Pretendia-se, por intermédio dele e à luz das novas concepções a respeito do processo de ensino aprendizagem, vencer a barreira da repetência logo no início da escolarização, promovendo uma profunda, ainda que gradual, mudança no mundo de atuar na escola. (SILVA; DAVIS, 1993, p.9).

${ }^{4}$ Devem-se registrar iniciativas entusiásticas semelhantes, naquele período, por parte de piagetianas de destaque, como: Esther Pillar Grossi, do GEEMPA - Grupo de Estudos sobre Educação, Metodologia de Pesquisa e Ação, em Porto Alegre/RS; e Terezinha Nunes Carraher, especialmente quando chefiou o Centro Pedagógico da Universidade Federal de Pernambuco. 
A teoria construtivista foi gradativamente ganhando espaço e sendo adotada em propostas educacionais de outros estados e municípios brasileiros, em decorrência de articulações e ações governamentais, envolvendo vultosos investimentos financeiros e muitos esforços de autoridades educacionais para convencer sobre sua relevância e sua viabilidade política e pedagógica. Na década de 1990, essa teoria se consolidou em nível federal, especialmente por meio dos Parâmetros Curriculares Nacionais (BRASIL, 1997) e hoje integra a Base Nacional Curricular Comum (BRASIL, 2016), em elaboração. Assim,

[...] tornaram-se verdade científica e universal as explicações do construtivismo sobre como a criança (todas elas e independentemente do contexto histórico, social e cultural em que vivem) constrói seu conhecimento sobre a escrita. Como se se tratasse de descoberta científica de uma evidência, de um fato preexistente, desconsidera-se que a delimitação e a compreensão desse "fato psicológico" são possibilitadas justamente pela teoria que as embasa e que sua explicação é um "constructo teórico", cujas "provas empíricas" são passíveis de muitos questionamentos. (MORTATTI, 2011b, p.45, grifo do original).

E como parte essencial do "aparato hegemônico", foi criado um novo terreno ideológico, determinante de uma "reforma das consciências" (GRAMSCI, 1978), ou seja, de novos modos de pensar e praticar o ensino de leitura e escrita - com base na teoria da "psicogênese da língua escrita”. (MORTATTI, 2014a, p.18).

De acordo com o construtivismo, passou-se a enfatizar a aprendizagem da lectoescrita, do ponto de vista da psicogênese da língua escrita, fundamentada na Epistemologia Genética de Piaget (1970). Nesse sentido, o foco do processo de alfabetização está em como a criança aprende a língua escrita, ou seja, como, na condição de sujeito cognoscente, constrói o conhecimento sobre a língua escrita, na interação com esse objeto de conhecimento ${ }^{5}$.

Trata-se, portanto, de uma teoria da aprendizagem/aquisição da língua escrita, que não comporta nem uma teoria do ensino, nem uma didática da leitura e da escrita. Essa característica epistemológica não impediu, no entanto, que pesquisadores e professores brasileiros "construíssem" paradoxais "didáticas construtivistas" ou "cartilhas construtivistas" e as apresentassem como equivocadas decorrências didáticopedagógicas dessa teoria e como um novo "método" de alfabetização. Como resultado

5 Para detalhamento dessa teoria e de sua apropriação no Brasil, ver, especialmente, Mello (2008) e Mortatti (2000). 
da combinação dos métodos tradicionais e da medida do nível de maturidade com as implicações pedagógicas das pesquisas de Ferreiro, esse "novo método" se baseia em diagnóstico, por meio de procedimentos e perguntas às crianças semelhantes aos do método clínico utilizado nas pesquisas de Ferreiro, e posterior classificação dos alfabetizandos em níveis "pré-silábicos", "silábicos", "silábico-alfabéticos" e "alfabéticos". A partir dessa classificação, o professor deve desenvolver um "trabalho didático" que respeite a realidade da criança e seu ritmo de construção do conhecimento.

Por meio da reiteração dessas apropriações ecléticas, foi se configurando um "construtivismo à brasileira", relacionado com um "conceito brasileiro de alfabetização" (MORTATTI, 2011a) $^{6}$. Nesse processo, as apropriações consensuais elaboradas principalmente por gestores e pesquisadores foram sendo incorporadas em políticas públicas, em discursos oficias ${ }^{7}$, em pesquisas acadêmicas, em cursos de formação inicial e continuada de professores alfabetizadores e em ações de ensino e aprendizagem iniciais de leitura e escrita.

Tendo passado a integrar o senso comum pedagógico, essas apropriações vêm até hoje embasando e conduzindo "naturalmente" a prática docente de gerações de alfabetizadores brasileiros, que provavelmente nunca leram, de fato, os textos de Ferreiro e colaboradores. E, por extensão, repercutem, de forma silenciosa, mas modelar, no ensino e na aprendizagem de leitura e escrita e das demais matérias e anos escolares, (de)formando a relação dos alunos com a língua escrita, mesmo depois de concluído, ou interrompido, seu processo de escolarização formal na Educação Básica (MORTATTI, 2014a).

E, com o aprofundamento das dificuldades de alunos da escola pública brasileira em aprender a ler e escrever e o alinhamento de políticas educacionais com padrões internacionais estabelecidos em função de políticas neoliberais de desenvolvimento econômico ${ }^{8}$, vem se mantendo a equivocada perspectiva segundo a qual o ensino de

${ }^{6}$ Alfabetização - "[...] termo/conceito utilizado contemporaneamente, no Brasil, para designar processo de ensino e aprendizagem que [...] comportou diferentes sentidos e foi designado por diferentes termos, correspondentes a diferentes conceitos, tais como: 'ensino das primeiras letras'; 'ensino de leitura'; 'ensino simultâneo de leitura e escrita'. A utilização do termo 'alfabetização' consolidou-se, no Brasil, a partir do início do século XX, sempre relacionado predominantemente com processos de escolarização; e, a partir das décadas finais desse século, passou a ser utilizado tanto em sentido amplo ('alfabetização matemática', 'alfabetização digital', dentre outros) quanto em sentido mais restrito e específico: 'ensinoaprendizagem inicial de leitura e escrita"”. (MORTATTI, 2011a, p.8).

${ }^{7}$ Sobre a relação promíscua entre discurso acadêmico e discurso oficial em relação ao ensino de leitura e escrita, ver, especialmente, Mortatti (2010).

${ }^{8}$ A esse respeito, ver Mortatti (2013). 
leitura e escrita deve se restringir ao acanhado patamar representado pelas "expectativas de aprendizagem" dos rudimentos da leitura e da escrita (MORTATTI, 2014a).

Por meio de mecanismos como os mencionados até aqui, ao longo do processo de hegemonização do construtivismo, neutralizaram-se a ambiguidade e a heterogeneidade entre seus propositores iniciais e sua condição inicial de "pedagogia de esquerda", tendo se tornado, a partir da década de 1990, uma pedagogia alinhada oportunamente às diretrizes neoliberais sintetizadas no lema "aprender a aprender" (DUARTE, 2008).

Embora não se possa nem se deva estabelecer relação direta entre nível de escolarização e nível de (an)alfabetismo, nem se deva atribuir exclusivamente ao construtivismo responsabilidades pelos problemas apontados, essas três décadas de hegemonia do construtivismo na alfabetização escolar demandam reflexões sobre a relação entre promessas e concretizações. Dados do IBGE - Instituto Brasileiro de Geografia e Estatística, do Relatório Educação para Todos (BRASIL, 2015) e do INAF

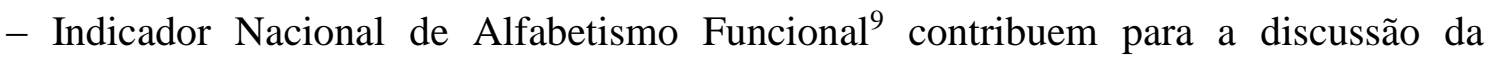
hipótese proposta para discussão do tema deste artigo. Dentre esses, destaco os do INAF (INSTITUTO PAULO MONTENEGRO, 2016), porque a metodologia utilizada não se restringe à autodeclaração do respondente e abrange a relação com ensino superior.

9 "O INAF é uma pesquisa realizada pelo Instituto Paulo Montenegro (2016) em parceria com a ONG Ação Educativa e com o IBOPE, que mensura o nível de alfabetismo funcional da população brasileira entre 15 e 64 anos, avaliando suas habilidades e práticas de leitura, de escrita e de realização de cálculos aplicadas ao cotidiano. [...] Segundo a escala Inaf, o grau de domínio das habilidades de leitura, escrita e matemática demonstrado pelos participantes do estudo permitem a identificação de dois grupos: Analfabetos Funcionais - Analfabeto - Corresponde à condição dos que não conseguem realizar tarefas simples que envolvem a leitura de palavras e frases ainda que uma parcela destes consiga ler números familiares (números de telefone, preços etc.); Rudimentar - Corresponde à capacidade de localizar uma informação explícita em textos curtos e familiares (como um anúncio ou um bilhete), ler e escrever números usuais e realizar operações simples, como manusear dinheiro para o pagamento de pequenas quantias ou fazer medidas de comprimento usando a fita métrica; Funcionalmente Alfabetizados ; [...] Elementar - As pessoas classificadas neste nível podem ser consideradas funcionalmente alfabetizadas, pois já leem e compreendem textos de média extensão, localizam informações mesmo que seja necessário realizar pequenas inferências, resolvem problemas envolvendo operações na ordem dos milhares, resolvem problemas envolvendo uma sequência simples de operações e compreendem gráficos ou tabelas simples, em contextos usuais. Mostram, no entanto, limitações quando as operações requeridas envolvem maior número de elementos, etapas ou relações; Intermediário - Localizam informações em diversos tipos de texto, resolvem problemas envolvendo percentagem ou proporções ou que requerem critérios de seleção de informações, elaboração e controle de etapas sucessivas para sua solução. As pessoas classificadas nesse nível interpretam e elaboram sínteses de textos diversos e reconhecem figuras de linguagem; no entanto, têm dificuldades para perceber e opinar sobre o posicionamento do autor de um texto. Proficientes - Classificadas neste nível estão as pessoas cujas habilidades não mais impõem restrições para compreender e interpretar textos em situações usuais: leem textos de maior complexidade, analisando e relacionando suas partes, comparam e avaliam informações e distinguem fato de opinião. Quanto à matemática, interpretam tabelas e gráficos com mais de duas variáveis, compreendendo elementos como escala, tendências e projeções. (INSTITUTO PAULO MONTENEGRO, 2016, p.5). 
Comparando resultados obtidos entre 2001 (primeira edição) e 2011, no relatório do INAF se conclui que, ao longo dessa década, houve:

[...] lenta, porém, progressiva ampliação da escolaridade da população, sobretudo em razão da ampliação do atendimento na educação básica para crianças e jovens. Nesse sentido, pode-se verificar ao longo de suas edições a melhoria nas condições de alfabetismo da população jovem e adulta brasileira, com redução significativa da proporção de pessoas nos níveis mais baixos, aumento nos níveis intermediários e, inesperadamente, uma estagnação da proporção de pessoas no grupo mais alto da escala de proficiência do INAF. (INSTITUTO PAULO MONTENEGRO, 2016, p.1, grifo nosso).

Ainda segundo esses resultados, “[...] apenas $8 \%$ dos respondentes estão no último grupo de alfabetismo, revelando domínio de habilidades que praticamente não mais impõem restrições para compreender e interpretar textos em situações usuais e resolvem problemas envolvendo múltiplas etapas, operações e informações”. (INSTITUTO PAULO MONTENEGRO, 2016, p.7, grifo nosso).

No estudo se conclui, ainda, que

[...] a escolaridade revela-se como um dos principais fatores explicativos da condição de alfabetismo. Há uma maior proporção de participantes nos grupos de maior desempenho na escala de alfabetismo conforme maior a escolaridade desses sujeitos. Entretanto, observa-se também que essa relação não ocorre de maneira uniforme ou linear: significativa proporção de pessoas que, mesmo tendo chegado ao ensino médio e à educação superior, por exemplo, não consegue alcançar o grupo mais alto da escala de alfabetismo. (INSTITUTO PAULO MONTENEGRO, 2016, p.8, grifo nosso).

\section{Construtivismo e formação de alfabetizadores e de pesquisadores}

Como parte do "aparato hegemônico", o construtivismo repercutiu e repercute diretamente na formação inicial de professores alfabetizadores, atualmente no curso de Pedagogia, e em sua formação continuada, por meio de programas e compromissos institucionais, como o PROFA - Programa de Formação de Professores Alfabetizadores e o PNAIC - Pacto Nacional pela Alfabetização na Idade Certa.

Dentre os saberes necessários especialmente para a função de alfabetizar, a partir da década de 1980 passaram a ser enfatizados os fundamentos e as aplicações da teoria 
construtivista, em especial a fundamentação teórica centrada na Epistemologia Genética e as "didáticas construtivistas" contidas em documentos oficiais (MORTATTI, 2008). Dadas as constantes dificuldades dos professores em aprender (se convencer) e em aplicar adequadamente as propostas decorrentes dessa teoria, foram se aperfeiçoando e consolidando recursos didático-pedagógicos para a atividade escolar, foi se caracterizando a função do professor como apenas a de "facilitador", “diagnosticador/avaliador", “incentivador”, "treinador para avaliações padronizadas", e o processo de ensino se tornou subordinado ao "ritmo de aprendizagem" dos alunos e às suas condições sociais e culturais (além de aos processos de avaliação padronizados de estudantes e sistemas de ensino), caracterizando-se a educação formal como um meio de adequação e conformação a fins preestabelecidos e autoexplicáveis.

Entretanto, apesar da rápida disseminação da teoria e das "didáticas construtivistas", as discussões e propostas para alfabetização escolar no Brasil se articularam de forma hegemônica, mas não exclusiva, em torno do construtivismo. $\mathrm{Na}$ década de 1980, foram também divulgados, outros estudos visando a outra compreensão do processo de ensino e de aprendizagem da leitura e escrita. Dentre esses, destacam-se os desenvolvidos pioneiramente pelos pesquisadores João Wanderley Geraldi e Ana Luiza Smolka. Formulando o problema de outro ponto de vista e em outras bases teóricas e políticas, centradas no interacionismo linguístico e na psicologia "soviética"10, esses pesquisadores propõem outra explicação para as dificuldades de as crianças aprenderem leitura e escrita e apresentam outras propostas para esse ensino ${ }^{11}$ (MORTATTI, 2007, 2014a).

Desse ponto de vista, essas propostas se configuraram e ainda se configuram como propostas contra-hegemônicas em relação às políticas educacionais questionadas na década de 1980, assim como em relação ao construtivismo. A proposta de Geraldi,

${ }^{10}$ Assim denominávamos na década de 1980 (anteriormente à dissolução da União Soviética) estudos de psicólogos, como L. S. Vygotsky, A. Luria e A. Leontiev, cujos textos começavam a ser traduzidos e divulgados no Brasil.

11 Além dessas propostas apresentadas na década de 1980, deve-se destacar que, na década seguinte, o modelo do "letramento (escolar)", foi introduzido no Brasil por meio de estudos das pesquisadoras brasileiras Angela Kleiman, Leda Tfouni e Magda Soares. A esse respeito, ver, especialmente Mortatti (2004, 2007). No início da década de 2000, alguns pesquisadores brasileiros apresentaram a proposta de alfabetização de crianças centrada no "novo" método fônico. Não se trata, porém, nem de novo modelo explicativo nem de inovação, pois, no século XIX, no Brasil, o método fônico (marcha sintética) foi utilizado e depois combatido como "tradicional". Representantes atuais desse método criticam veemente o construtivismo, mas, devo ressaltar, com motivações, finalidades e interesses políticos e econômicos dos quais discordo e que divergem dos que apresento neste artigo. A esse respeito, ver, especialmente, Mortatti (2009). 
em especial, apresenta uma nova (ainda hoje) didática da leitura e escrita, centrada no texto e na qual se relacionam os diferentes aspectos envolvidos nesse processo discursivo, os quais respondem às perguntas: “[...] por que, para que, como, o que, quando, onde, quem, com quem ensinar e aprender a língua escrita?" (MORTATTI, 2007, p.59).

Essa proposta foi bastante divulgada a partir da década de 1980 em vários estados brasileiros, por meio tanto do livro "O texto na sala de aula", organizado por Geraldi (1984), quanto das assessorias por ele prestadas ${ }^{12}$. Em que pese sua extensa difusão, essa proposta não se tornou hegemônica, possivelmente por causa de articulações em torno de disputas político-educacionais, no âmbito de secretarias de educação ou de universidades, protagonizadas pelos defensores do construtivismo. No entanto, mesmo que diferentes do ponto de vista epistemológico, formulações e práticas características dessa proposta - tais como "trabalho com texto", "produção de texto" - foram sendo equivocadamente apresentadas no discurso oficial e incorporadas às "didáticas construtivistas", de forma meramente justaposta e como se ambas fossem complementares entre si (MORTATTI, 2014a) ${ }^{13}$. Como solução "conciliadora", criaram-se novas classificações, tais como, "socioconstrutivismo", "construtivismo interacionista", "pós-construtivismo".

De ponto de vista político e teórico diferentes do construtivismo, a proposta de Geraldi se fundamenta em conceito de linguagem como forma de interação e de texto como unidade de sentido e objeto de ensino e aprendizagem da leitura e escrita. Por esse motivo, essa proposta

[...] se caracterizou e ainda se caracteriza como "contra-hegemônica", porque formulada com base em outro paradigma teórico. Funda, assim, novos sentidos para os conceitos de leitura, escrita e texto, propiciando a formulação de questões não restritas a como se ensina, nem a como se aprende, porque visam a responder aos diferentes aspectos dessa atividade especificamente humana e política: por que, para que, quem, para/com quem, quando, onde, o que e como ensinar e aprender (língua portuguesa e literatura).

${ }^{12}$ Esse projeto foi coordenado por Geraldi e contou com a participação ativa das professoras Lilian Lopes Martin Silva, da Faculdade de Educação/Unicamp, e Raquel Salek Fiad e Denise Bértoli Braga, ambas do IEL/Unicamp.

${ }^{13}$ Processo semelhante ocorreu com teorias do desenvolvimento cognitivo da criança propostas por J. Piaget e L. S. Vygotsky, tendo se iniciado, na década de 1990, os contundentes debates entre defensores brasileiros de cada uma dessas teorias. Como exemplo, pode-se mencionar o artigo de Souza e Kramer (1991). 
Nesse sentido e em contradiscurso, a proposta sintetizada em $\mathbf{O}$ texto na sala de aula [...] representou e ainda representa revolução conceitual (uma outra) consistente, com impacto qualitativo em todas as dimensões (didático-pedagógica, cultural, social e política) do processo de ensino-aprendizagem de língua portuguesa e literatura. Esse impacto pode ser estendido também às demais matérias/disciplinas escolares assim como à compreensão mesma da educação (escolar) como momento privilegiado de formação humana/política dos sujeitos sócio-históricos. (MORTATTI, 2014a, p.23, grifo do original).

Síntese ilustrativa de seus fundamentos se encontra no já clássico artigo "Escrita, uso da escrita e avaliação" (GERALDI, 1984), em que, para discutir a avaliação da escrita e o conceito de texto em oposição ao de redação, o autor apresenta os dois "textos" transcritos abaixo. O primeiro deles foi escrito por aluno que, em 1983, frequentava a $2^{\mathrm{a}}$ série do $1^{\mathrm{o}}$ grau, porque tinha sido considerado alfabetizado e foi aprovado na $1^{\text {a }}$ série. O segundo foi escrito por aluno que, em 1984, repetia a $1^{\text {a }}$ série, porque tinha sido considerado não alfabetizado.

\author{
A casa é bonita. \\ A casa é do menino. \\ A casa é do pai. \\ A casa tem uma sala. \\ A casa é amarela. (GERALDI, 1984, p.122).
}

Era uma vez um pionho queroia ocabelo daí um emninopinhento dapasou um umenino lipo enei pionho aí pasou um emnino pionhento daí omenino pegoupionoho da amunhér pegoupionho da todomundosaiugritãdo todomundo pegoupionho di até sofinho begou pionho. (GERALDI, 1984, p.123).

Considerando que propostas metodológicas articulam concepções políticas, o autor analisa os dois "textos" acima e conclui que: o primeiro pode ser considerado "redação" escolar, pois seu "[...] autor apenas devolve, por escrito, o que a escola lhe disse, na forma como a escola lhe disse. Anula-se, pois, o sujeito. Nasce o alunofunção. Eis a redação.” (GERALDI, 1984, p.123, grifo do autor); o segundo, ao contrário,

[...] usa a modalidade escrita para contar uma história. Ainda que [...] a leitura possa ser prejudicada por problemas ortográficos e estruturais, há aqui de fato um texto, e não mera redação. Na verdade, o autor ainda não aprendeu o jogo da escola: insiste em dizer sua palavra. Foi reprovado e repete a primeira série. (GERALDI, 1984, p.123, grifo do autor). 
Os autores dos textos analisados por Geraldi (1984) eram "filhos" das ideias e práticas alfabetizadoras questionadas pelas "pedagogias de esquerda" na década de 1980. No entanto, os problemas que esses textos evidenciam ainda persistem na "alfabetização construtivista", à qual foram e são submetidos aqueles que cursam(ram) Ensino Fundamental e Médio nas últimas décadas. Esse é o caso dos alunos da disciplina "Conteúdo, metodologia e prática de ensino (CMPE): língua portuguesa e literatura infantill”, que ministro no curso de Pedagogia. Com duração de 75 horas-aula, durante um semestre letivo, a disciplina integra a grade curricular do $3^{\circ}$ ano desse curso de formação de professores para a Educação Infantil e Anos Iniciais do Ensino Fundamental.

A carga horária da disciplina representa um evidente paradoxo, que se repete em todas as disciplinas similares do curso voltadas especificamente para a formação de professores para a docência das matérias do currículo dos Anos Iniciais do Ensino Fundamental. Nesse curto período de tempo, para (de forma minimamente adequada) ensinar a ensinar leitura e escrita entendidas como ensino de língua portuguesa, é necessário grande esforço, exceto, talvez, para os que aceitam pelo menos três premissas falsas e complementares entre si: a) os professorandos já dominam o conteúdo de leitura e escrita que devem ensinar, uma vez que já cursaram o mesmo nível de ensino onde atuarão como docentes; b) ensinar a ler e a escrever é observar/diagnosticar/avaliar os níveis de aquisição da escrita dos alunos e treiná-los para bom desempenho em testes padronizados; c) por esses motivos, deve-se apenas ensinar/treinar os professorandos a aplicar/executar atividades didáticas, como "facilitadores", “diagnosticadores/avaliadores", “incentivadores", "treinadores para avaliações padronizadas", decorrentes de programas e projetos governamentais construtivistas, ou seja, trata-se de mera questão procedimental, que envolve o "como fazer", conforme o lema do "aprender a aprender".

Embora pareçam absurdas, essas premissas estão na base da perpetuação da hegemonia do construtivismo e da formação de "professores construtivistas". No entanto, com base em outra premissa, formar professores é ensinar a conceber/executar/avaliar projetos de ensino, a conhecer opções e tomar decisões responsáveis entre seus fundamentos teóricos e suas implicações didáticas (MORTATTI, 2008).

Com esse objetivo e considerando as limitações e as precárias condições de muitos dos alunos dos cursos de formação de professores, elaborei plano de ensino com 
informações, conceitos e leituras que considero essenciais para que os futuros professores conheçam a história de ensino de leitura e escrita no Brasil e aprendam ao menos as principais características de diferentes teorias sobre o tema, em especial para problematizar as certezas e verdades decorrentes da "naturalização" do construtivismo e das falsas premissas em que se assenta sua formação como aluno e como professor. E, assim, aprendam, ao menos, outras possibilidades de reflexão/ação, não como "discursos sobre" essas possibilidades, mas como vivência efetiva em seu processo de formação como alunos que serão professores.

A constatação mais urgente e necessária é a de que, depois de 11 anos de escolaridade, alunos professorandos que ensinarão a ler e escrever não sabem ler e produzir textos, nem podem ser considerados "proficientes”, ou seja, “[...] pessoas cujas habilidades não mais impõem restrições para compreender e interpretar textos em situações usuais: leem textos de maior complexidade, analisando e relacionando suas partes, comparam e avaliam informações e distinguem fato de opinião". (INSTITUTO PAULO MONTENEGRO, 2016, [S.n.]).

Considerando as diferenças etárias e de nível de escolarização assim como de proposta e de tipologia textual, podemos encontrar muitas semelhanças entre aqueles textos (descritivo e narrativo) analisados por Geraldi (1984) e o texto dissertativoargumentativo apresentado na Figura 1, produzido pela aluna B. C. O. na disciplina mencionada, com o objetivo de discorrer sobre o ensino de língua portuguesa do ponto de vista do interacionismo linguístico, com base no livro de Geraldi (1984), que foi objeto de estudo durante as aulas. 
Figura 1 - Texto da aluna B. C. O.

No livro O Texto Na Sala de Aula tem vários artigos de alguns professores de português, e Geraldi relata sobre a educação, leitura, analise e produção de textos, ele nos faz refletir sobre a prática de ensino e como os alunos aprendem dentro e fora da escola, que o ensino tradicional da gramatica não tem significação para o aluno, que somente vai passando de ano sem entender o conteúdo de um texto com um olhar crítico e analítico e isso dificulta que o aluno possa se expressar melhor na hora de escrever. (1982 apud LAJOLO; M. p. 53) "Leitor maduro é aquele para quem cada nova leitura desloca e altera o significado de tudo que ele já leu, tornando mais profunda sua compreensão dos livros, das gentes e da vida".

$\mathrm{O}$ autor propõe aos professores que durante as aulas utilizem livros e principalmente textos para desenvolver a leitura, escrita e analíse dos textos abordados em sala de aula, e durante as correções dos textos produzidos não devemos ficar buscando os erros, mas estar atentos para descobrir o que o aluno já sabe e ajuda-lo a entender o que ainda não percebeu, auxiliando na hora de escrever já que a pratica de escrita é uma e a oralidade é outra,e isso é muito importante durante a alfabetização porque o nosso idioma possui muitas variedades, então o aluno precisa ver que é fundamental seguir a norma culta.

Sendo assim o ideal é que o aluno escolha o livro que vai ler, observando os detalhes da capa, o resumo da obra e isso tudo vai abrindo o apetite para saber qual o final da história estando totalmente enredado pelo encanto das palavras e a forma com que o conteúdo o faz imaginar e pensar sobre o assunto tratado. Então ele se sente convidado a ler outros livros e sendo assim ele aceita porque um convite agradável é impossível dizer não, até porque ler é essencial para a vida assim como a água, é uma Sede de aprender que nunca acaba!

Fonte: Acervo pessoal da autora.

É evidente o esforço de autoria, conceito básico estudado na disciplina. Mas também é evidente a falta de recursos adequados para a compreensão ativa de autoria nos processos de leitura e escrita de textos como processos de produção de sentidos. Os equívocos e incoerências teóricas em relação ao conteúdo e aos conceitos básicos do interacionismo linguístico, os problemas de coerência e coesão textuais, a dificuldade de compreender as diferenças entre oralidade e escrita, evidenciada pela predominância de sintaxe coordenativa característica da linguagem oral, o estilo de "dissertação de vestibular", dentre outros aspectos, indicam semelhanças com a "redação" escolar. 
Com raríssimas exceções, esse texto é representativo dos que produzem os demais alunos de cursos de graduação de instituições públicas e particulares, especialmente nos cursos de formação de professores, onde predominam egressos de escolas públicas, pertencentes às "classes populares" ${ }^{14}$ e também representativo dos que produzem estudantes de pós-graduação [...]

Complementando o círculo vicioso, nesse "novo terreno ideológico" que, a partir da década de 1980, vem determinando modos de pensar e praticar o ensino e a aprendizagem de leitura e escrita, também se dá a formação de pesquisadores e professores universitários em programas de pós-graduação stricto sensu. Às dificuldades de leitura e escrita acumuladas por esses pós-graduandos em sua formação educacional anterior se acrescenta sua condição de "neófitos" na Academia e mais propensos a se submeterem a demandas imediatistas e pressões advindas de cumprimento de prazos exíguos e critérios de avaliação produtivistas a que são submetidos os resultados de suas pesquisas. E tendem a "acolher" temas e problemas de pesquisa recorrrentes e também hegemônicos na pesquisa sobre alfabetização, relacionados direta ou indiretamente com o construtivismo (MORTATTI, 2014b).

Nesse contexto, a produção acadêmica de mestrandos e doutorandos vem também interagindo, de forma reativa, com políticas públicas, que, por sua vez, têm alto impacto na definição de temas e problemas de pesquisa acadêmica relacionados com alfabetização e construtivismo (MORTATTI, 2010, 2014b). Assim, muitas teses e dissertações sobre o tema "[...] indicam consolidação de tendência à reprodução de 'verdades inquestionáveis', como forma de, submetendo-se a normas e prazos impostos por organismos reguladores, garantir obtenção de financiamentos públicos e, sobretudo, de títulos acadêmicos.” (MORTATTI; OLIVEIRA; PASQUIN, 2014, p.27, grifo do original).

Frente a essas constatações, somos instados a indagar: se professores não sabem ler e produzir textos, como podem ensinar seus alunos a ler e produzir textos? Se professores não sabem refletir sobre seu objeto de ensino - leitura e produção de

${ }^{14}$ De acordo com estudo de Pinho, Spazziani e Oliveira (2016), relativo ao perfil dos ingressantes na UNESP - Universidade Estadual Paulista, nos cursos de graduação da área de Ciências Humanas, entre 2006 e 2015, destacam-se as seguintes conclusões: “[...] realizaram todo o ensino fundamental em escola pública, com porcentagem crescente a partir de 2010, chegando a 54\% em 2013. A porcentagem dos egressos de escola particular vem decrescendo ligeiramente de 2010 até 2013, mas nos anos seguintes apresenta valores crescentes." (PINHO; SPAZZIANI; OLIVEIRA, 2016, p.173). Quanto ao Ensino médio: "[...] a participação de egressos de escola particular é praticamente igual à dos egressos de escola pública nos três primeiros anos, com predominância dos últimos nos três anos seguintes". (PINHO; SPAZZIANI; OLIVEIRA, 2016, p.174). 
textos - , se não podem participar de processos de concepção e avaliação de propostas de ensino, como poderão se constituir como sujeitos sócio-históricos conscientes de sua função social como professores e responsáveis por suas escolhas para contribuir para a constituição de outros sujeitos sócio-históricos? Se pós-graduados também têm dificuldades de leitura e escrita, como poderão exercer suas funções de professores universitários e orientadores de trabalhos acadêmicos? Se não conseguem estabelecer diálogo crítico com as teorias hegemônicas em alfabetização, como poderão contribuir para avanços na produção de conhecimentos científicos em educação?

\section{Considerações finais}

Considerando o processo de "reforma das consciências", com base no qual, há pelo menos 30 anos, vêm sendo "formadas" gerações de brasileiros e seus formadores, da educação básica à pós-graduação, a perpetuação da hegemonia do construtivismo em alfabetização escolar no Brasil é hoje o signo ideológico mais evidente da "politicidade intrínseca" (FREIRE, 2001) da alfabetização escolar como campo de disputas por projetos de nação.

Esse movimento histórico, por sua vez, indica a tendência a se estender, ainda por largo espaço de tempo, a hegemonia do "construtivismo à brasileira". Para isso, concorre o processo de naturalização que transformou (?) a "revolução conceitual" em mito, ou seja, em narrativa que explica e demonstra a psicogênese da língua escrita na criança. Posto em ação por meio de ritos reiterados à exaustão, esse mito é hoje uma crença (compartilhada em todos os níveis da educação nacional), que organiza a realidade objetiva da alfabetização escolar, ordena a visão de mundo sobre esse processo, legitima ações de correção dos erros do passado em nome da salvação do presente e de promessas de futuro. E os efeitos desse "aparato ideológico" são agravados por pelo menos dois aspectos mais evidentes: 
[...] os resultados das pesquisas de Ferreiro não foram ainda contestados em sua base teórica, permanecendo atuantes, portanto, sua validade científica e sua condição de fundadora de uma nova tradição no que diz respeito ao ensino-aprendizagem da língua escrita na fase inicial de escolarização de crianças; e o fato de que a assunção oficial das novas teorias não comporta retrocessos e ainda está a demandar reiteradas versões positivas, dada a ênfase na ideia de "revolução" e no investimento político, por parte de grupos que ainda se mantêm [e se renovam] no poder [...]. (MORTATTI, 2000, p.286).

Neutralizadas as contradições (sem conflitos) entre forças antagônicas (?) possivelmente existentes entre os que inicialmente defenderam a introdução da teoria construtivista no Brasil, somos hoje instados a inevitáveis indagações: a introdução do construtivismo no Brasil resultou de falta de opções didático-pedagógicas condizentes com a reorganização das forças políticas de esquerda no processo de redemocratização do país? Ou se tratou de opção mesmo, respaldada pela condição de necessária novidade científica patrocinada por intelectuais que equivocadamente eram (auto) considerados de esquerda? Caracterizava-se como contra-hegemônica, de fato? Esteve, de fato, a serviço do almejado e combativo processo de redemocratização do país e da educação? A que levou o construtivismo em alfabetização escolar no Brasil?

Ao longo das últimas três últimas décadas, o processo de democratização do país vem caminhando em sobressaltos, com alguns avanços e muitos retrocessos e muitíssimas contradições, com algumas conquistas e muitíssimas perdas, nos âmbitos político, econômico, social e educacional. E, em que pesem os avanços quantitativos na educação pública e as boas intenções político-pedagógicas anunciadas inicialmente pelos defensores do construtivismo, vêm se "perdendo" para o analfabetismo funcional gerações de brasileiros, que têm engrossado as fileiras dos deserdados das promessas de inclusão no mundo público da leitura e escrita.

Articulando a essas as perdas históricas da sociedade brasileira (especialmente na sombria conjuntura atual), constata-se que, em substituição àqueles "filhos do analfabetismo" que motivaram as pesquisas de Emilia Ferreiro, há hoje milhões de brasileiros (incluindo estudantes, professores e pesquisadores) que partilham de outra trágica condição social e política: a dos "órfãos do construtivismo".

Esse é o problema político-educacional basilar a ser enfrentado, com urgência, pelos educadores e pesquisadores "de esquerda", no século XXI. E, para isso, impõe-se a urgente necessidade de coragem política e ousadia intelectual que fundamente o compromisso de professores e pesquisadores compreenderem os problemas do 
construtivismo, em especial do "construtivismo à brasileira" e formularem perguntas cujas respostas são ainda desconhecidas e demandam esforço conjunto e concentrado dos que sabem que ensinar e aprender a ler e escrever são atividades imprescindíveis para a constituição de nossa condição humana.

\section{REFERÊNCIAS}

BRASIL. Ministério da Educação. Base Nacional Curricular Comum. Brasília: Governo Federal, 2016. Disponível em: <http://basenacionalcomum.mec.gov.br/\#/site/inicio>. Acesso em: 12 dez. 2016.

BRASIL. Ministério da Educação. Parâmetros Curriculares Nacionais. Secretaria de Educação Fundamental. Brasília: MEC/SEF, 1997.

BRASIL. Ministério da Educação. Relatório Educação para Todos no Brasil 20002015. Versão Preliminar. Brasília: MEC, 2015. Disponível em: <http://portal.mec.gov.br/index.php?option=com_docman\&view=download\&alias=157 74-ept-relatorio-06062014\&Itemid=30192 > . Acesso em: 8 dez. 2016.

DUARTE, N. Por que é necessário uma análise crítica marxista do construtivismo? In: LOMBARDI, J. C.; SAVIANI, D. (Org.). Marxismo e educação: debates contemporâneos. 2.ed. Campinas: Autores Associados; HISTEDBR, 2008. p.203-221.

FERREIRO, E. (Org.). Os filhos do analfabetismo: propostas para a alfabetização escolar na América Latina. Tradução de M. L. M. Abaurre. 3.ed. Porto Alegre: Artes Médicas, 1990.

FREIRE, P. Educação como prática da liberdade. 25.ed. Rio de Janeiro: Paz e Terra, 2001.

GERALDI, J. W. (Org.). O texto na sala de aula: leitura \& produção. Cascavel: Assoeste, 1984.

INSTITUTO PAULO MONTENEGRO. INAF - Indicador de alfabetismo funcional. Estudo especial sobre alfabetismo e mundo do trabalho. São Paulo: Instituto Paulo Montenegro. Ação Social do IBOPE, 2016. Disponível em: <file:///C:/Users/ss1011639/Downloads/INAFEstudosEspeciais_2016_Letramento_e_M undo_do_Trabalho.pdf>. Acesso em: 12 dez. 2016.

MELLO, M. C. O. Emilia Ferreiro e a alfabetização no Brasil: um estudo sobre a psicogênese da língua escrita. São Paulo: Ed. da UNESP, 2008.

MORTATTI, M. R. L. A "querela dos métodos" de alfabetização no Brasil: contribuições para metodizar o debate. Acolhendo a Alfabetização nos Países de 
Língua Portuguesa, São Paulo, v.3, n.5, 2009. Disponível em: <http://www.revistas.usp.br/reaa/article/view/11509>. Acesso em: 8 nov. 2016.

MORTATTI, M. R. L. Alfabetização no Brasil: conjecturas sobre as relações entre políticas públicas e seus sujeitos privados. Revista Brasileira de Educação, Rio de Janeiro, v.15, $2010 . \quad$ Disponível em: $<$ http://www.scielo.br/scielo.php?script=sci_abstract\&pid=S1413-

24782010000200009\&lng=pt\&nrm=iso\&tlng=pt>. Acesso em: 8 nov. 2016.

MORTATTI, M. R. L. (Org.). Alfabetização no Brasil: uma história de sua história. Marília: Oficina Universitária, 2011a. Disponível em: <http://www.marilia.unesp.br/Home/Publicacoes/alfabetizacao.pdf >. Acesso em: 8 nov. 2016.

MORTATTI, M. R. L. Educação e letramento. São Paulo: Ed. da UNESP, 2004.

MORTATTI, M. R. L. Função social da escola: aspectos históricos e metodológicos da alfabetização In: CHAVES, M.; SETOGUTI, R.; VOLSI, M. A função social da escola: das políticas públicas às práticas pedagógicas. Maringá: Ed. da UEM, 2011b. p.35-60.

MORTATTI, M. R. L. Letrar é preciso, alfabetizar não basta... mais? In: SCHOLZE, L.; RÖSING, T. M. K. (Org.). Teorias e práticas do letramento. Brasília: MEC/INEP, $2007 . \quad$ p.155-168. Disponível em: file://C:/Users/ss1011639/Downloads/\%7B71A1445D-FD55-462B-AC0FF6E106D3DD98\%7D_MIOLO_Teorias_Praticas_Letramento.pdf >. Acesso em: 12 dez. 2016.

MORTATTI, M. R. L. Notas para uma história da formação do alfabetizador no Brasil. Revista Brasileira de Estudos Pedagógicos, Brasília, v.89, n.223, p.467-476, 2008. Disponível em: <http://rbep.inep.gov.br/index.php/rbep/article/view/687>. Acesso em: 8 nov. 2016

MORTATTI, M. R. L. Os sentidos da alfabetização: São Paulo 1876/1994. São Paulo: Ed. da UNESP, 2000.

MORTATTI, M. R. L. O texto na sala de aula: uma revolução conceitual na história do ensino de língua e literatura no Brasil. In: SILVA, L. L. M.; FERREIRA, N. S. A.; MORTATTI, M. R. L. (Org.). O texto na sala de aula: um clássico sobre ensino de língua portuguesa. Campinas: Autores Associados, 2014a. p.5-28.

MORTATTI, M. R. L. Produção acadêmica brasileira sobre alfabetização: avaliação da qualidade e impacto científico e social. In: MORTATTI, M. R. L; FRADE, I.C.A. (Org..). Alfabetização e seus sentidos: o que sabemos, queremos e fazemos. Marília: Oficina Universitária, 2014b. p.131-158. Disponível em: <http://www.marilia.unesp.br/Home/Publicacoes/alfabetizacao_ebook.pdf >. Acesso em: 8 nov. 2016.

MORTATTI, M. R. L. Um balanço crítico da "Década da Alfabetização" no Brasil. Cadernos CEDES, Campinas, v.33, n.89, p.15-34, 2013. Disponível em: 
<http://www.scielo.br/scielo.php?pid=S0101-

32622013000100002\&script=sci_abstract\&tlng=pt>. Acesso em: 8 nov. 2016.

MORTATTI, M. R. L.; OLIVEIRA, F. R.; PASQUIN, F. R. 50 anos de produção acadêmica brasileira sobre alfabetização: avanços, contradições e desafios. Interfaces da Educação, Paranaíba, v.5, n.13, p.6-31, 2014. Disponível em: <http://www.periodicosonlilne.uems.br/index.php/interfaces/article/viewFile/486/452>. Acesso em: 8 nov. 2016.

PIAGET, J. Epistemologia genética. Petrópolis: Vozes, 1970.

PINHO, S. Z.; SPAZZIANI, M. L.; OLIVEIRA, J. B. B. Perfil socioeconômico e sociocultural dos ingressantes nos cursos de graduação - 2006-2015. São Paulo: UNESP, 2016.

SAVIANI, D. Teorias pedagógicas contra-hegemônicas no Brasil. Revista Ideação, Feira de Santana, v.10, n.2, p.11-28, 2008.

SILVA, R. N.; DAVIS, C. É proibido repetir. Estudos em Avaliação Educacional, São Paulo, n.7, p.5-44, jan./jun. 1993.

SOUZA, S. J.; KRAMER, S. O debate Piaget/Vygotsky e as políticas educacionais. Cadernos de Pesquisa, São Paulo, n.77, p.69-80, mai. 1991.

\section{Como referenciar este artigo}

MORTATTI, Maria do Rosário Longo. Os órfãos do construtivismo. Revista IberoAmericana de Estudos em Educação, Araraquara, v. 11, n. esp. 4, p.2267-2286, 2016. Disponível em: <https://dx.doi.org/10.21723/riaee.v11.esp4.9193>. E-ISSN: 19825587.

Submetido em: setembro/2016

Aprovado em: novembro/2016 